\title{
Epidemiological Pattern of Closed Femoral Shaft Fractures in a Regional Tertiary Hospital in Enugu, Nigeria
}

\author{
E. C. Iyidobi ${ }^{1}$, R. T. Ekwunife ${ }^{1}$, U. M. Enweani ${ }^{2}$, C. U. Nwadinigwe1, I. C. Okwesili ${ }^{3}$, \\ H. C. Ekwedigwe ${ }^{4}$ \\ ${ }^{1}$ National Orthopedic Hospital, Enugu, Nigeria \\ ${ }^{2}$ City Specialist Hospital, Enugu, Nigeria \\ ${ }^{3}$ College of Medicine, University of Nigeria, Eungu, Campus \\ ${ }^{4}$ Enugu State University Teaching Hospital Parklane, Enugu, Nigeria \\ Email: dreciyidobi@yahoo.com, ^remyclassic@yahoo.com,Ug_enweani@yahoo.com,cunwadinigwe@yahoo.co.uk, \\ ikeokwesili@gmail.com, ekwedyte@yahoo.com
}

How to cite this paper: Iyidobi, E.C. Ekwunife, R.T., Enweani, U.M., Nwadinigwe, C.U., Okwesili, I.C. and Ekwedigwe, H.C. (2019) Epidemiological Pattern of Closed Femoral Shaft Fractures in a Regional Tertiary Hospital in Enugu, Nigeria. Journal of Biosciences and Medicines, 7, 180-188.

https://doi.org/10.4236/jbm.2019.75019

Received: April 6, 2019

Accepted: May 24, 2019

Published: May 27, 2019

Copyright ( 2019 by author(s) and Scientific Research Publishing Inc. This work is licensed under the Creative Commons Attribution International License (CC BY 4.0).

http://creativecommons.org/licenses/by/4.0/ (c) (i) Open Access

\begin{abstract}
Background: The femur is the longest and strongest tubular bone in the human body. The femoral shaft is the portion of the bone between $5 \mathrm{~cm}$ distal to the lesser trochanter and $6 \mathrm{~cm}$ proximal to the most distal point of the medial femoral condyle. Femoral shaft fractures often result from high energy forces. These fractures occur mostly among young adults. Objective: This was to determine the epidemiological pattern of closed femoral shaft fractures in a regional tertiary hospital in Enugu, Nigeria. Method: The study was a prospective study over a 12 month period (June 2015-May 2016) at National Orthopaedic Hospital, Enugu. Following ethical approval and written informed consent, patients were consecutively recruited. The patients were clinically and radiographically evaluated at presentation. The diagnosis of closed femoral shaft fractures were made from the physical examination finding of absent open wound communicating with the fracture hematoma in the thigh and anteroposterior (AP) and lateral $\mathrm{x}$-rays of the affected thigh confirming the fracture pattern. The data collected included patients' demographics, the cause of injury, the side of injury and anatomic site of the injury among other parameters. The data were collected using well designed and structured proforma. Results: A total of 52 femoral shaft fractures in 50 patients were included and analyzed using SPSS version 20.0. The age range of the patients is $18-85$ years with a median age of $39.1 \pm 14.9$ years. The most commonly affected age group is 21 - 30 years. There was male preponderance with a male to female ratio of 2.3:1. Majority of the fractures (76.9\%) resulted from road traffic crashes most commonly following motor vehicular accident
\end{abstract}


(36.5\%). Majority of the fractures (92.3\%) are unilateral with right side to left side ratio of 1.2:1. Majority of the patients (51.9\%) had Winquist Hansen grade III type of fracture. The most common associated injury is fractures of tibia/fibula followed by fracture of the neck of the ipsilateral femur. All the patients were treated operatively using either locked intramedullary nailing technique or plating technique. Majority of the patients (59.6\%) were discharged between 10th and 29th day post-operatively. Conclusion: From the results of this study, it is concluded that most of the closed femoral shaft fractures were caused by high energy trauma from road traffic crashes. It is therefore recommended that proper education of motorists on good use of roads and strict adherence to traffic rules will significantly help in preventing the occurrence of these fractures in our environment.

\section{Keywords}

Epidemiology, Closed, Femoral Shaft Fracture

\section{Introduction}

The femur is the longest, strongest, largest and heaviest tubular bone in the human body [1] [2] [3] [4] [5]. It is one of the principal load-bearing bones in the lower extremity [5]. It is essential for normal ambulation. It has a surrounding layer of very strong and powerful muscles [6] [7]. The femur consists of three parts namely femoral shaft or diaphysis, proximal metaphysis and distal metaphysis. The femoral shaft is the portion of the bone between $5 \mathrm{~cm}$ distal to the lesser trochanter and $6 \mathrm{~cm}$ proximal to the most distal point of the medial femoral condyle [8]. Femoral shaft fractures often result from high energy forces associated with possible multiple system injuries [2] [5] [9]. Low energy violence can also cause these fractures especially among the elderly [10] [11]. In the United States, the incidence is $1-1.310,000$ populations/year [12]. It is most common in males younger than 30 years. The average number of days lost from work or school is 30 days while the average number of days of restricted activity is 107 days [12]. The spectrum of femoral shaft fractures ranges from non-displaced femoral stress fractures to fractures associated with severe comminution and significant soft tissue injury. There are several classifications for femoral shaft fractures but none is yet universally acceptable [6]. However, the classification by Winquist and Hansen based on the degree of comminution and instability has direct use in operative decision making and planning and as such it is now widely used [13] [14]. It is also very objective and straight forward to apply using the plain X-rays done to confirm the diagnosis of the fracture. Plain X-rays of the affected thigh with the hip and knee joints in two views (anteroposterior and lateral views) confirm the diagnosis. The X-rays will also show the level and pattern of the fracture. There might be a need to X-ray other regions such as the pelvis, chest, etc for associated injuries in some cases [7]. The definitive treat- 
ment involves anatomic reduction and stabilization. Several techniques have been developed for the treatment. However, most femoral shaft fractures are treated surgically with intramedullary nailing or plate fixation [12]. The aim of the study was to determine the epidemiological pattern of closed femoral shaft fractures in a regional tertiary hospital in Enugu, Nigeria. The findings will help to improve preventive strategies against these fractures in our environment.

\section{Methodology}

The study was a prospective study over a 12 month period (June 2015-May 2016) at National Orthopaedic Hospital, Enugu. Ethical clearance was obtained from the hospital ethical committee. Written informed consent was obtained from all prospectively recruited participants. The inclusion criteria were patients aged 18 years and above admitted at NOHE with closed femoral shaft fracture(s). Patients who presented more than 4 weeks after their injuries, as well as those who refused to give written informed consent were excluded from the study. Physical examination finding of absent open wound communicating with the fracture hematoma in the thigh and plain X-rays of the affected thigh with the hip and knee joints in two views (anteroposterior and lateral views) were done to confirm the diagnosis. Patients who met the inclusion criteria following clinical evaluation and radiological assessment at presentation were consecutively recruited for the study. All the patients had internal fixation of their fracture with either plating or locked intramedullary nailing technique. The data were collected using well designed and structured proforma. The data included the patients' demographics, cause of injury, side of injury, anatomical site of fracture, Winquist-Hansen class of the fracture, date of injury, date of admission in the hospital, date of operation, type of internal fixation done. The data generated were presented in texts, tables, figures and graphs. The data collated were coded, entered and analysed with electronic computer software, Statistical Package for Social Science (SPSS) version 20.0. Descriptive statistics which includes frequency, percent, mean, median, and standard deviation were used to summarize categorical and continuous variables.

\section{Results}

A total of 52 closed femoral shaft fractures in 50 patients (26 fractures in each group) were included in the study and analyzed. The age range of the patients is 18 - 85 years with a median age of $39.1 \pm 14.9$ years.

Table 1 shows that the most commonly affected age group is 21 - 30 years.

Figure 1 shows male preponderance with a male to female ratio of 2.3:1.

Figure 2 shows that the majority of the patients (86.5\%) presented to the hospital within 5 days of sustaining their fracture.

Figure 3 shows that the majority of the fractures (76.9\%) resulted from road traffic crashes most commonly following motor vehicular accident (36.5\%).

Figure 4 shows that the majority of the fractures (92.3\%) are unilateral with 
right side to left side ratio of 1.2:1.

Table 2 shows that the most common associated injury is fractures of tibia/fibula followed by fracture of the neck of the ipsilateral femur.

Table 3 shows that the most common anatomic site of fracture is the distal third of the femoral shaft.

Table 4 shows that Winquist-Hansen type 3 grade of fractures is the most common variety encountered.

Table 5(a) shows that the majority of the patients (59.6\%) were discharged between 10th and 29th day of admission.

Table 5(b) shows the hospital admission duration range and median.

Table 1. Age distribution of the patients.

\begin{tabular}{ccc}
\hline Age (years) & Frequency & Percent \\
\hline $11-20$ & 4 & 7.7 \\
$21-30$ & 14 & 26.9 \\
$31-40$ & 13 & 25.0 \\
$41-50$ & 11 & 21.2 \\
$51-60$ & 4 & 7.7 \\
$>60$ & 6 & 11.5 \\
Total & $\mathbf{5 2}$ & 100.0 \\
\hline
\end{tabular}

Table 2. Associated Injuries in the Patients.

\begin{tabular}{ccc}
\hline Other Injuries & Frequency & Percent \\
\hline Fractures of tibia/fibular & 10 & 25.6 \\
Fracture neck of ipsilateral femur & 5 & 12.8 \\
Head injury & 4 & 10.3 \\
Ankle/foot injury & 4 & 10.3 \\
Clavicular fracture & 3 & 7.7 \\
Fractures of radius/ulna & 3 & 7.7 \\
Fracture of distal radius & 2 & 5.1 \\
Facial injury & 2 & 5.1 \\
Shoulder dislocation & 1 & 2.6 \\
Pelvic injury & 1 & 2.6 \\
Fracture of proximal humerus & 1 & 2.6 \\
Spinal cord injury with paraplegia & 1 & 2.6 \\
Knee injury & 1 & 2.6 \\
Blunt chest injury & 1 & 2.6 \\
Total & 39 & 100.0 \\
\hline
\end{tabular}


Table 3. Distribution of the anatomic site of injury.

\begin{tabular}{ccc}
\hline Anatomic Site of Injury & Frequency & Percent \\
\hline Proximal & 17 & 32.7 \\
Middle & 15 & 28.8 \\
Distal & 20 & 38.5 \\
Total & $\mathbf{5 2}$ & $\mathbf{1 0 0 . 0}$ \\
\hline
\end{tabular}

Table 4. Distribution of the Winquist-Hansen grades of the fractures.

\begin{tabular}{ccc}
\hline Winquist-Hansen Type & Frequency & Percent \\
\hline Type 1 & 20 & 38.5 \\
Type 2 & 5 & 9.6 \\
Type 3 & 27 & 51.9 \\
Type 4 & 0 & 0.0 \\
Total & $\mathbf{5 2}$ & $\mathbf{1 0 0 . 0}$ \\
\hline
\end{tabular}

Table 5. (a) Distribution of Number of Days of Hospital Admission; (b) Duration of Hospital Admission.

(a)

\begin{tabular}{ccc}
\hline Days on Admission & Frequency & Percent \\
\hline $0-9$ & 3 & 5.8 \\
$10-19$ & 16 & 30.8 \\
$20-29$ & 15 & 28.8 \\
$30-39$ & 7 & 13.5 \\
$40-49$ & 6 & 11.5 \\
$50-59$ & 2 & 3.8 \\
$60-69$ & 1 & 1.9 \\
70 \& above & 2 & 3.8 \\
Total & $\mathbf{5 2 ~ 1 1}$ & 100.0 \\
\hline
\end{tabular}

(b)

\begin{tabular}{cccc}
\hline $\mathbf{N}$ & $\begin{array}{c}\text { Minimum } \\
\text { (Days) }\end{array}$ & $\begin{array}{c}\text { Maximum } \\
\text { (Days) }\end{array}$ & $\begin{array}{c}\text { Median } \\
\text { (Days) }\end{array}$ \\
\hline 52 & 6.00 & 98.00 & 23.00 \\
\hline
\end{tabular}

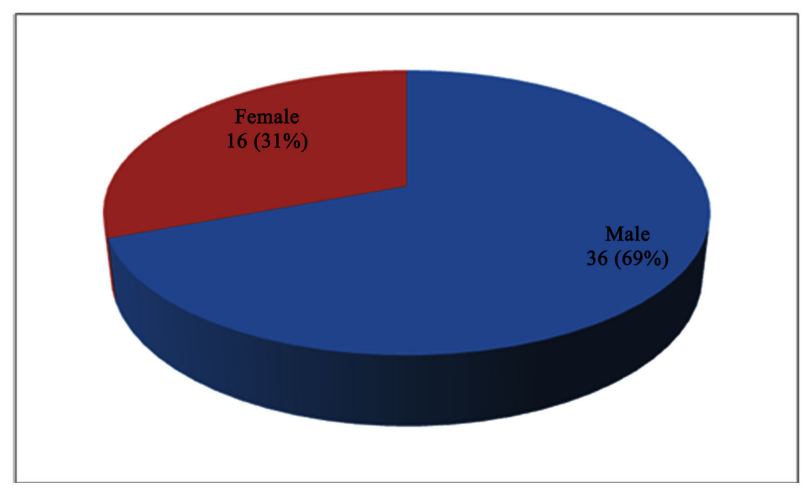

Figure 1. Sex Distribution of the Patients. 


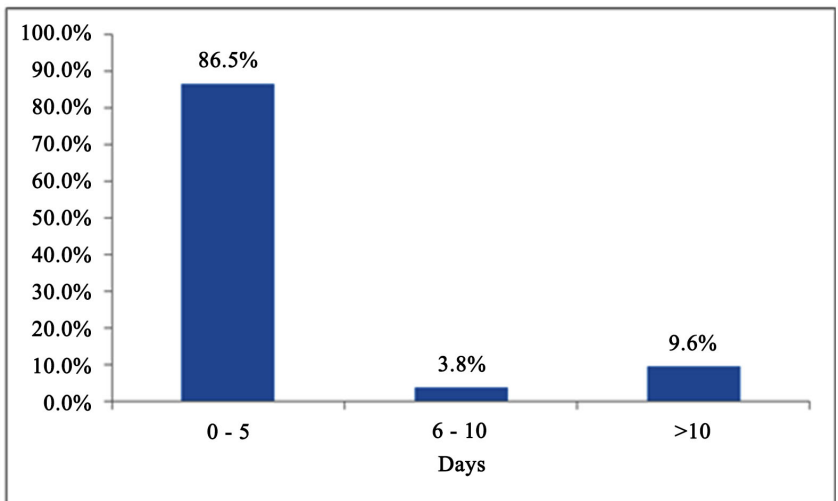

Figure 2. Time Interval between Injury and Presentation to the Hospital.

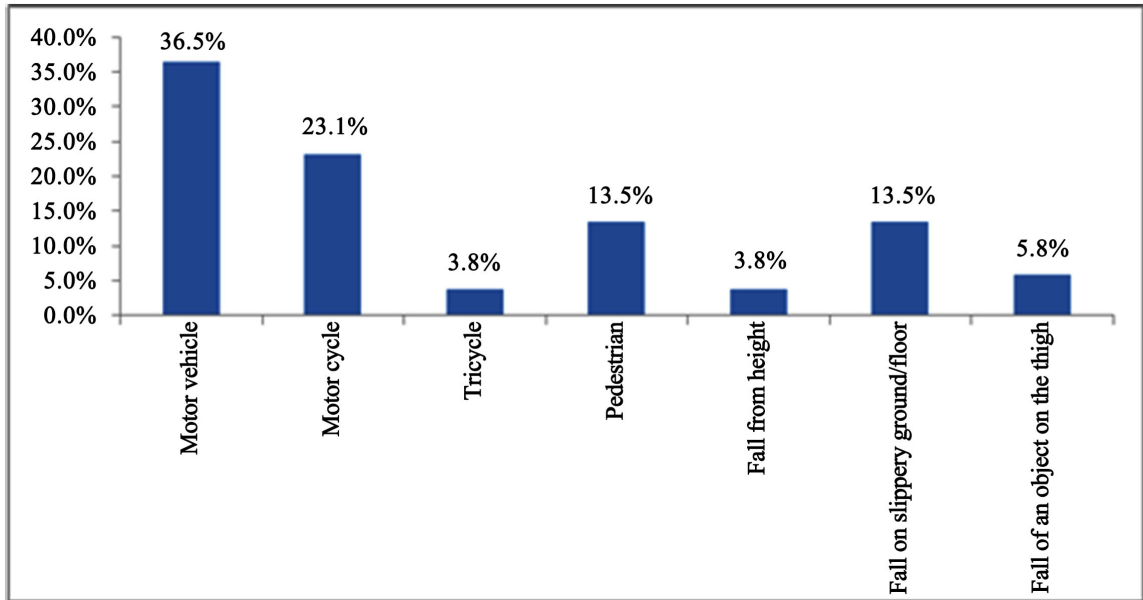

Figure 3. Cause of Injury.

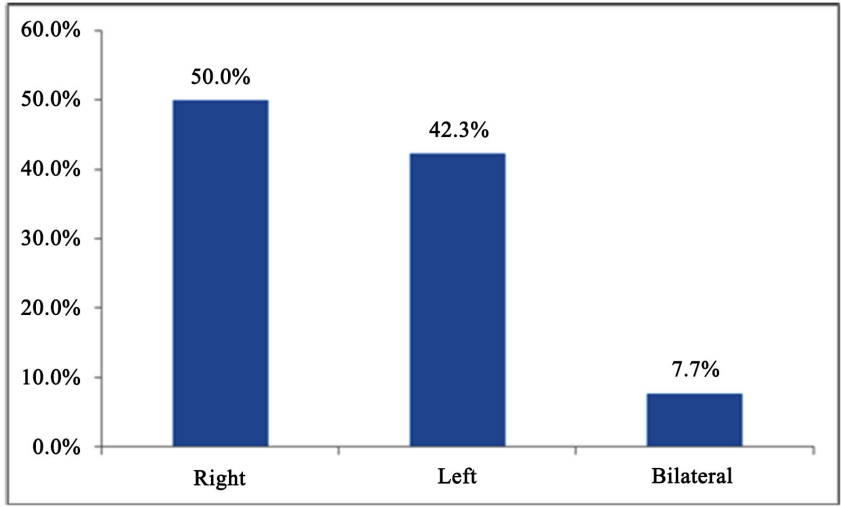

Figure 4. Side of Injury.

\section{Discussions}

This was a prospective study on epidemiological pattern of fresh closed femoral shaft fractures presenting in a regional tertiary hospital. It highlights the patients' demographic status, the causes of the fractures, the side and anatomic site of the fracture, as well as the Winquist-Hansen classification of the fractures among other parameters. 
Femoral shaft fractures were found to occur most commonly within the age range of 21 - 40 years with a peak age range of $21-30$ years. This is similar to the findings by Felix [15], Katchy et al. [16] and Oginni et al. [17] where the most commonly involved age bracket was also found to be $21-45$ years. It also agrees with the documentations in other literature that noted femoral shaft fractures to occur most commonly in males younger than 30 years [12] [14]. Similarly, the average age of affected patients of $39.1 \pm 14.86$ years found in the study agrees with the mean age of $33 \pm 11.6$ years reported by Felix [15] and 35 years reported by Dim et al. [14] in their series. The study also found a male preponderance with male to female ratio of 2.3:1 which is within the ratio of 1.5:1 to 2.7:1 already reported by some researchers [8] [14] [18] [19]. However, this differed slightly from the ratio of 1.1:1 in the study group and 1.7:1 in the control group found by Dim in his study at National Orthopaedic Hospital, Igbobi, Lagos [20]. The ratio is also lower than 6:1 and 3:1 reported respectively by Salawu and Iwegbu in Zaria in their studies [21]. These differences are probably due to the influence of the population being studied on the distribution of adult femoral shaft fractures [20] [21]. However, the overall male preponderance is probably because of their higher activity levels than females.

Majority of the fractures (76.9\%) resulted from road traffic crashes. This is similar to the prevalence of $88.7 \%$ reported by Iwegbu in Zaria and prevalence of $68 \%$ reported by Jensen et al. in a Denmark hospital from road crashes [21]. However, it is slightly lower than the prevalence of $97 \%$ reported by Salawu in his series [21]. This difference may be attributable to the influence of the society studied on the cause of adult femoral shaft fractures. Also, the proportion of the fractures $(17.3 \%)$ that resulted from falls is similar to the proportion of $19.6 \%$ reported by Jensen et al. in their study [21].

Majority of the fractures (92.3\%) were unilateral involving either the right or the left femoral shaft. This agrees with the proportion of $93.6 \%$ reported by Magerl et al. in their study [22]. Also, there is a slight preponderance of right side fractures in these unilateral cases which is similar to the finding by Dim in his study at National Orthopaedic Hospital Igbobi Lagos [20]. However, this differs from the equal affectation of both sides reported by Magerl et al. [22] and the left side predilection reported by Kootstra in his series (54.4\% versus $45.6 \%$ ) [23]. These differences may be due to the differences in the environments of the population studied. Also, the preponderance of distal third fractures found in the study differed from the documentation in some literature that reported middle third fractures as the most common [8] [20] [24] [25]. The study found $12-18$ weeks average time of bone union of the majority of the fractures (92.3\%). This was similar to the average time of bone union of femoral shaft fractures following internal fixation reported by Salminen in his study [26]. The overall bone union rate of $92.3 \%$ found in the study at 18 weeks also agrees with the overall rate of $90 \%-100 \%$ reported by Magerl et al. [22] and Warmbrod et al. [27] in their series. 


\section{Conclusion}

From the results of this study, it is concluded that road traffic crashes is the most common cause of closed femoral shaft fractures in our environment. Also, most of the victims were young male adults within the age bracket of $21-40$ years. It is therefore recommended that proper education of motorists and young adults on good use of roads and strict adherence to traffic rules will significantly help in preventing the occurrence of these fractures. However, some of the patients who met the inclusion criteria refused to give written informed consent to participate in the study despite explanation thereby limiting the sample size for the study.

\section{Conflicts of Interest}

The authors declare no conflicts of interest regarding the publication of this paper.

\section{References}

[1] Moore, K.L. and Dalley, A.F. (2006) Clinically Oriented Anatomy. 5th Edition, Lippincott Williams and Wilkins, Baltimore, 556-717.

[2] Bucholz, R. and Brumback, R. (1996) Rockwood and Green's Fractures in Adult: Fractures of the Shaft of the Femur. 4th Edition, Lippincott-Raven, Philadelphia, 1827-1918.

[3] Schatzter, J. and Tile, M. (1996) The Rationale of Operative Fracture Care: Fractures of the Femur. Springer-Verlag, Berlin, Heidelberg, New York, 367-386. https://doi.org/10.1007/978-3-642-88443-6 16

[4] Platzer, W. (2003) Colour Altas of Human Anatomy: Locomotor System. 5th Edition, Thieme Verlag, Stuttgart, New York.

[5] Canale, S.T. and Beaty, J.H. (2008) Campbell's Operative Orthopaedics: Fractures of Lower Extremity. 11th Edition, Mosby, an Imprint of Elsevier, Philadelphia, 2825-2872.

[6] James, E.K. and Rick, K. (2011) Femur Fractures. http://emedicine.medscape.com/article/824856

[7] Louis, S., David, W. and Selvadurai, N. (2010) Apley's System of Orthopaedics and Fracture. 9th Edition, Hodder Arnold, an Hachette UK Company, London, 859-872.

[8] Dencker, H.M. (1963) Fractures of the Shaft of Femur: A Clinical Study Based on 1003 Fractures Treated in Swedish Hospitals during the Three-Year Period 1952-54. Thesis, University of Gothenbury, Gothenburg, 1-135.

[9] Bucholz, R.W. and Jones, A. (1991) Fractures of the Shaft of the Femur. The Journal of Bone and Joint Surgery. American Volume, 73, 1561-1566. https://doi.org/10.2106/00004623-199173100-00015

[10] Wong, P.C.N. (1966) An Epidemiological Appraisal of Femoral Shaft Fractures in a Mixed Asian Population-Singapore. Singapore Medical Journal, 7, 236-239.

[11] Hedlund, R. and Lindgren, U. (1986) Epidemiolgy of Diaplyseal Femoral Fracture. Acta Orthopaedica Scandinavica, 57, 423-427. https://doi.org/10.3109/17453678609014762

[12] Douglas, F.A., John, R.D. and Janos, P.E. (2011) Femur Injuries and Fractures. http://emedicine.medscaoe.com/article/90779

[13] Winquist, R.A., Hansen Jr., S.T. and Clawson, D.K. (1984) Closed Intramedullary 
Nailing of Femoral Fractures: A Report of Five Hundred and Twenty Cases. The Journal of Bone and Joint Surgery, American Volume, 66, 529-539. https://doi.org/10.2106/00004623-198466040-00006

[14] Dim, E.M., Ugwuegbulem, O.A. and Ugbeye, M.E. (2012) Adult Traumatic Femoral Shaft Fractures: A Review of the Literatures. IBOM Medical Journal, 5, 26-38.

[15] Felix, S.M. (2012) Short-Term Outcome of Patients with Closed Comminuted Femoral Shaft Fractures Treated with Locking Intramedullary SIGN Nailing at $\mathrm{Mu}$ himbili Orthopaedic Institute (MOI). Dissertation for Degree of Master of Medicine in Orthopaedics and Traumatology, Muhilnbili Universtiy of Health and Allied Sciences, Tanzania, 1-67.

[16] Katchy, A.U., Agu, T.C. and Nwankwo, O.E. (2000) Femoral Shaft Fractures in a Regional Setting. Nigerian Journal of Medicine, 9, 138-140.

[17] Oginni, L.M., Mathew, R., Thomas, F. and Adigun, A. (1993) Femoral Shaft Fractures in Ilesha. Nigerian Medical Journal, 24, 62-64.

[18] Bostman, O., Varjonen, L., Vaninonpaa, S., Majola, A. and Rokkanen, P. (1989) Incidence of Local Complications after Intramedullary Nailing and after Plate Fixation of Femoral Shaft Fractures. The Journal of Trauma, 29, 639-645. https://doi.org/10.1097/00005373-198905000-00019

[19] Harry, A.M. (2001) Kuntscher Nailing of Traumatic Femoral Shaft Fractures: Length and Cost of Hospital Stay in the National Orthopaedic Hospital Lagos. FMCS Dissertation, NPMCN, 1-39.

[20] Dim, E.M. (2007) Open Reduction and Internal Fixation for Femoral Shaft Fractures: An Assessment of the Use of Intramedullary Nailing and Plate Fixation at National Orthopaedic Hospital Igbobi, Lagos, Nigeria. Dissertation, NPMCN, 1-80.

[21] Salawu, S.A.I. (1985) A Comparative Study of the Methods of Treating Fractures of the Middle Third of the Adult Femoral Shaft in Zaria. FMCS Dissertation, NPMCN, $1-65$.

[22] Magerl, F., Wyss, A., Brunner, C.H. and Binger, W. (1979) Plate Osteosynthesis of Femoral Shaft Fractures in Adults. Clinical Orthopaedics and Related Research, $138,62-73$.

[23] Kootsra, G. (1973) Femoral Shaft Fractures in Adult: A Study of 329 Consecutive Cases with a Statistical Analysis of Different Methods of Treatment. Thesis, Van Gorcum and Comp. B.V Assen. Unversity of Groningen, Groningen.

[24] Arneson, T.J., Melton, L.J., Lewallen, D.G. and O’Fallon, W.M. (1998) Epidemiology of Diaphyseal and Distal Femoral Fractures in Rochester, Minnesota, 1965-1984. Clinical Orthopaedics and Related Research, 234, 188-194. https://doi.org/10.1097/00003086-198809000-00033

[25] Oyemade, G.A.A. and Oluwole, S. (1978) The Pattern of Fractures in an African Community. Nigerian Medical Journal, 18, 21-24.

[26] Salminen, S. (2005) Femoral Shaft Fractures in Adults: Epidemiology Fracture Patterns, Non-Unions, and Fatigue Fractures. Academic Dissertation, University of Helsinki, Helsinki.

[27] Warmbrod, J.G., Yelton, C.L. and Weiss, A.B. (1996) Intramedullary Nailing of Femoral Shaft Fractures: Ten Years' Experience. Clinical Orthopaedics and Related Research, 114, 282-286. https://doi.org/10.1097/00003086-197601000-00033 